\title{
ANNS-BASED EARLY WARNING SYSTEM FOR INDONESIAN ISLAMIC BANKS
}

\author{
Saiful Anwar ${ }^{1}$, A.M. Hasan Ali²
}

\begin{abstract}
This research proposes a development of Early Warning System (EWS) model towards the financial performance of Islamic bank using financial ratios and macroeconomic indicators. The result of this paper is ready-to-use algorithm for the issue that needs to be solved shortly using machine learning technique which is not widely applied in Islamic banking. The research was conducted in three stages using Artificial Neural Networks (ANNs) technique: the selection of variables that significantly affect financial performance, developing an algorithm as a predictor and testing the predictor algorithm using out of sample data. Finally, the research concludes that the proposed model results in 100\% accuracy for predicting Islamic bank's financial conditions for the next two consecutive months.
\end{abstract}

Keywords: Early Warning System, Artificial Neural Networks, Islamic Banks, Financial Distress.

JEL Classification: C45, C53, G33, G21

1. Lecturer at STIE Ahmad Dahlan, Jakarta and Risk Oversight Committee, PT. Bank BRI Syariah. Email: olieanwar@gmail.com

2. Lecturer at UIN Syarif Hidayatullah, Jakarta Email: buya.fatia@gmail.com 


\section{INTRODUCTION}

The golden period experienced by Islamic banks has apparently been passed. The growth over $20 \%$ per year that occurred in 2009 until 2011 is continuously experiencing a decreasing trend. In 2012, Indonesian Central Bank reported that the growth of market shares of Islamic banks doubly decreased to $9.44 \%$ and further experienced a negative trend with a growth rate of $6.07 \%$ in 2013. Finally, for the first time in Indonesian Islamic Bank's development period, the market shares of Islamic banks experienced a negative growth of $4 \%$ in December 2014. The year actually became a difficult year for Islamic banking due to the increase of interest rate which caused the cost of bank funds to soar. In the first semester of 2013, the SBI interest rate stood still at 5.75\% which was then kept increasing towards $7.75 \%$ in October 2014. This growth rate had a direct impact on the increase of deposit rates of conventional banks as the competitors of Islamic banks in collecting thirdparty funds. At the end of 2014, one of the Islamic banks offered a profit sharing rate for its deposit products which was equivalent to $10 \%-11 \%$ of interest rate in order to compete with conventional banks which offered averagely $8.07 \%$ in the same period for the one month of deposit. The significant pressure on the cost of funds affected the growth rate of market shares of Islamic banking decreasing. The profit of Islamic bank grew only 15.1\% in 2014 compared with previous year which successfully reached $43.8 \%$ growth. The hard pressure towards Islamic bank's profit was triggered not only by the weakening of national economy marked by high inflation and the continuously weakening exchange rate but also due to the weakness of the Good Corporate Governance of Islamic banks.

The Non-Performing Financing (NPF) ratio of Islamic banks at the end of 2014 reached $4.33 \%$, a very significant increase compared with the previous period which was only $2.62 \%$. The more worrying conditions will be more clear when looking more detail at the absolute amount of NPF, whereas the default financing category increased to $2.24 \%$, amounted to Rp4.465 trillion. This is almost equal to the total amount of NPF in 2013 which amounted to Rp4.828 trillion. This condition got worse with the widespread news of fraud occurred in the biggest Islamic bank in Indonesia which loosed hundreds of billions of rupiahs, causing the increase of reputational risk for Islamic banking industry.

The condition has created excessive distressing which comes from the social and economic views. The excessive distressing appears since the Islamic banking industry employs around 42 thousand employees which their lives and families' welfare depend on. Additionally, it would decline the derivative industries such as education whereas thousands of schools and universities already offered Islamic finance subject and already attracted tens of thousands of students throughout Indonesia. The social turbulence with significant economic loss will surely happen when a particular Islamic bank experiences difficulty. This local problem could be spread out which then created systemic risk.

Further, the systemic risk in Islamic bank could degrade the reputation of Islamic bank as a type of business institution which uses the symbol of religion. This could be a boomerang for Islamic economic development wherein intensive socialization has been conducted about the fact that the Islamic economy with its financing instruments is thought as an alternative financing system. The system is expected to become a catalyst for economic fluctuations due to maysir (gambling), ghoror (speculation), and riba (interest) transaction (Chapra, 2009). 
Financial Services Authority (OJK) Act number 21 of 2011, the institution is mandated to organize a system of regulation and supervision which is integrated towards the entirety of activities in the financial services sector as to create a financial system condition which is organized, fair, transparent, and accountable, as well as to grow in a sustainable and stable way so that it is able to protect consumer and public interests. Accordingly, OJK has a responsibility to conduct preventive actions, one of which is to develop early warning system (EWS) for Islamic bank's failure detection. According to Indonesian, The EWS works to perform monitoring and supervision by providing signals indicating the probability of a declining in a bank's performance. According to that signals, the OJK can determine which banks are necessary to get strict supervision and give aid in a short time in the form of financing or managerial supervision to immediately pulled out the bank from bad conditions that probably lead towards bankruptcy.

Othman (2012) reveals that financial authority has two methods to develop EWS which are an on-site examination and off-site examination methods. The prior method is conducted by performing a direct assessment on the day to day banking operation. Pettway and Sinkey (1980) suggest EWS using accounting data and market information to determine the priority of the banks which need an onsite examination. Meanwhile, the off-site examination is a statistics or mathematics based method to determine the probability of a bank's bankruptcy (Othman, 2012). The effectivity of this method is measured according to its accuracy in classifying whether a particular bank is in a troubled or not compared to its actual condition.

Beaver (1966) is the first researcher who makes prediction using Univariate Discriminant Analysis method to make a prediction of bankruptcy. Two years after that, Altman (1968) introduced a model to predict a company's bankruptcy using Multiple-Discriminant Analysis (MDA) method which is now widely known as the Altman Z-score. In the 1980s, Takahashi (1984) and Friedmen et al. (1985) utilized the Recursive Partitioning Algorithm to predict bankruptcy. Bellovary et al. (2007) applied the statistical method and mathematical models to make a prediction. He observed many statistical and mathematical method starting from a simple statistical method until a complex data mining method such as neural networks.

Bellovary et al. (2007) reported that the use of the statistical method and data mining technique which introduced since year 1990s, resulted in a wide variety of accuracy. He observed 106 researchers who use statistical methods resulted in accuracy rate ranging from $24 \%$ to $94 \%$ in predicting a company's bankruptcy. Moreover, 40 researchers who use data mining techniques such as neural network resulted in accuracy rate ranging from $71 \%$ to $100 \%$. Liao et al. (2012) reported that the usage of data mining technique received more attention since the number of the researcher who uses the technique is rapidly growing. The technique has many types such as artificial neural network, clustering, association rule, artificial intelligence, bioinformatics, fuzzy logic, support vector machine and so forth. Particularly, for the case of Indonesian Islamic bank research, Anwar and Ismal (2011) reported that the artificial neural network method empirically possesses a higher accuracy rate compared to support vector machine method in predicting the profit sharing rate of Islamic banks in Indonesia. The result depicted that the artificial neural network model has a better ability in understanding the context of the diversity and volatility of data patterns. 
Accordingly, this research summarizes problems associated with Indonesian Islamic bank's performance that is necessary to solve, which are:

1. The decreasing of the financial performance of Islamic banks is considered to be main cause why many targets proclaimed by OJK are failed to be achieved such as the percentage of market share and profitability ratios.

2. The uniqueness of operational and business model of Islamic banks which lead to the special risks that are not found in conventional banks, such as displaced commercial risk and investment risk.

3. The very volatile economic conditions, such as the instability of exchange rates which causes the disturbance on achieving the growth rate targeted through the rise of credit risk and the liquidity problem in money market which creates difficulty to Islamic banks in obtaining a low cost of fund.

Therefore, it is necessary for Islamic banks to have EWS signaling the decreasing of financial performance. The EWS must be suitable with the characteristics and uniqueness of Islamic banks, ultimately in determining the best algorithms that understand those conditions properly. In order to answer the problems, the development of an EWS model is highly needed. For that purpose, this research will attempt to explore, to empirically test and to analyze as many as possible the reason for performance decrease in Islamic bank guided by research questions below:

1. What kind of variables could give negative impact to financial performance of Islamic banks?

2. How accurate are artificial neural networks (ANNs) as prediction algorithm in making a prediction (in term of accuracy)?

This research will use Bank Syariah Mandiri, the biggest Islamic bank in Indonesia, as a case study in measuring the accuracy and stability of ANNs as a prediction algorithm in EWS

\section{THEORY}

\subsection{Financial Distress}

The term of systemic risk is defined as the probability of severity that would affect other banks when a bank experiences problems. In another word, when a bank faces a financial decrease, it would possibly trigger financial decrease to other banks and at the end, the entire industry could be collapsed. This is why financial problems in a bank will frighten other parties and the economic system as a whole (Othman, 2012).

The financial problem was discussed by Altman (1993) who differentiated the conditions of a company's financial condition into four types: failure, insolvency, default, and bankruptcy. In detail, failure is a condition where the rate of return of money invested experiences a continuous decreasing which its value is less than return received in a similar industry. Meanwhile, insolvency is a condition where the company encounters difficulties in fulfilling its obligations at a certain time and temporary. If this insolvency continues for a long time, its conditions will lead to bankruptcy when the value of total obligation exceeds the value of total asset possessed by a company. 
This research uses financial distress term because the researcher believes that a business' failure is not something that suddenly happens. Certainly, there is a series of continuous signals alarming bad condition of a company, if the signal is ignored without some effort to make improvement so that the current condition will lead towards a bankruptcy. This is in line with Cybinski's (2001) opinion that explains the definition of financial distress as: "Failed and non-failed firms do not lie in separate boxes, but rather lie on a continuum of failed and non-failed".

In addition, Arena (2008) defines the character of a bank failure when the government performs recapitalization action in order to inject a sum of money or when that bank is identified as frozen which is disallowed conducting business.

Bankruptcy does not only happen to conventional banks, a few Islamic banks in the world also experience bankruptcy such as (Othman, 2012):

1. The International Islamic Bank of Denmark which was liquidized in 1986 due to channeling funding with an excessive exposure to a consumer.

2. The Islamic Investment Companies of Egypt which was closed in 1988 due to poor GCG, the lack of responsibility in the management, and the poor quality of the supervision which caused the bank to proceed transactions that do not comply with sharia law.

3. The closure of the Islamic Bank of South Africa in November 1997 due to its involvement in a debt amounting to R50-R70 million. This happened as the banking authority parties did not conduct enough supervision, consequently opening an opportunity for the management to commit fraud by channeling funding to related parties.

4. The Berhard Islamic Bank of Malaysia (BIMB) has experienced a significant loss at the end of June 2005. The loss suffered amounted to RM457 million due to a Non-Performing Financing amounted RM774 million.

5. The bankruptcy of the Ihlas Finance House (IFH) in Turkey in 2001. This happened due to poor GCG which the bank did transactions in the money market causing liquidity problem.

6. The failure to pay of sharia bonds issued by the Dubai World which requested restructuration of the debt payment amounted USD4 billion. This incident is known as the Dubai Debt Crisis due to its exorbitant amount.

7. The last case is the bankruptcy of the Arcapita Bank BSC. This bank was the first investment bank in America. The bankruptcy occurred when the bank failed to conduct an agreement with the creditor amounted USD1.1 billion for a syndication financing that the due date will be on March 28, 2012.

\subsection{Model of Bankruptcy}

The model of bankruptcy was first introduced by Meyer and Pifer in 1970. This research was continued by Martin (1977), Altman et. al (1981), Gunther (1983) and Espahbodi (1991). These four researchers have one similarity, which is the use of financial ratios as their independent variables to predict whether a bank will go bankrupt or not.

The initial researcher who predicts the bankruptcy of Islamic banks are AlOsaimy and Bamakhramah in 2004. Applying the Discriminant Analysis method, Al-Osaimy and Bamakhramah (2004) predicted the profitability of Islamic banks 
using financial ratios as independent variables. This model was followed by Hall, Mujawan, and Morena (2008) who conducted an analysis of the credit risks of Islamic banks by using the Artificial Neural Networks model.

\subsection{Decision Support System and The Algorithm}

Decision-making is the result of a highly complicated process aiming to anticipate the conditions that will occur in the future, be it the positive and beneficial ones or otherwise based on data, information, and modern knowledge and past experiences

This decision-making process begins with one's awareness who lives in a complex system and then continued by classifying external factors which are related to the problem. Afterward, the classification process will select the most significant factors that will be used as the basis for making a decision. The factors are then processed by using the additive factor employed as a prediction machine that will be used as a guide in the decision-making process. This prediction machine will ease someone in simplifying all the information which has already been classified beforehand and then providing options as predictions. Each option has been weighted which then to be chosen as the most suitable decision.

In the last few decades, humans have been assisted by the rapid development of information technology. This assistance is marked by the availability of state-ofthe-art useful software in making a decision on both company and individual levels. Specifically, in the financial industry, Wen et al. (2008) propose a knowledge-based decision support system using ANNs as a prediction algorithm that measures and predicts the financial performance of a company. Beforehand, Tsang et al. (2004) propose a software supporting decision-making process by predicting the investment performance of a company, this system is named as Evolutionary Dynamic Data Investment Evaluator (EDDIE) employing genetic programming as prediction algorithm.

In the theoretical approach, Matheson and Howard (1968) explained that the decision support system (DSS) is a system that implements scientific procedures in a highly complex situation where some one necessitates to make decisions. This system uses a computation model that will quantitatively evaluate every option offered and then gives a comparison by calculating the weight of each available option. Subsequently, the system gives a suggestion to the user in making the decision. In detail, Wen et al. (2008) explained the parts of a sub-system comprising a DSS as follows: (1) Data management subsystem. (2) Knowledge management subsystem. (3). Model management subsystem. (4) Dialogue subsystem.

As a system, each subsystem does not work alone, instead, the subsystem is being clustered and linked with each other to perform their duties in giving feedback and suggestions to the users. This DSS works initially by processing data in the data management subsystem. Afterwards, the DSS analyzes on each connection created to the whole successfully gathered data which are collected by the knowledge management subsystem. Next, the model management subsystem will model the data in which the results will be used to compare the available option as a basis for decisions according to the best-weighted factor. The best available option is then suggested to the users and displayed on the dialogue subsystem. 
ANNs is one of the branches of machine learning method which simulates the workings of a nervous system. This model works in groups and has a structure consisting of cells called neurons forming a neural network that similar to the human brain. The elements which support a neuron's operation comprise input, weight functioning as a learning method, transformation function which will determine whether the incoming information is important enough to be forwarded to other neurons by comparing the weight of the information according to its threshold. Similar to the human brain, neurons in ANNs require a training process to perform a comprehension process such as recognizing patterns, generalizing a problem, and conducting a self-study to improve capabilities in doing analyses and drawing conclusions.

Technically, ANNs work as follows. Starting from a neuron called j possessing a few sources of input such as $\left(x_{1}, x_{2}, x_{3}, \ldots, x_{j}\right)$ and an output $\left(y_{j}\right)$. Each input coming into the $\mathrm{j}$ neuron that has a weight in the form of $\left(\mathrm{w}_{1 j^{\prime}}, \mathrm{w}_{2 \mathrm{j}^{\prime}}, \mathrm{w}_{3 \mathrm{j}^{\prime}}, \ldots, \mathrm{w}_{\mathrm{ij}}\right)$ defined as the level of urgency from each input. Then, information that entering the $\mathrm{j}$ neuron is the sum of all the value of the incoming information multiplied by each of its weight so called the net value $\left(u_{i}\right)$. Next, the $u_{j}$ will be compared with the threshold $\left(t_{i}\right)$ of the $\mathrm{j}$ neuron and simultaneously determined whether the incoming information will be sent to the next neuron where each neuron has different $t_{j}$ values. If $u_{j}$ is larger than $t_{i}$, then the $j$ neuron will process and then send it to other neurons in the form of an output $\left(\mathrm{y}_{\mathrm{j}}\right)$. To do this, the neuron needs a function called the activation function which is responsible for activating the $u_{j}$ and transforming it into $y_{j}$. The most often used function as activation is the logistic and sigmoid functions.

The typology or architecture of ANNs that most often used in a research is multilayered (West et al., 1997). Therefore, this research will combine a few neurons in a multilayered form to be used in pattern recognition such as conducting a classification and a prediction. This multilayer is in the form of a feed-forward network consisting of the input layer, hidden layers, and output layer. Mathematically, the ANN model is written as follows:

$$
y=f(x, \theta)+\varepsilon
$$

Wherein: $x$ is a vector of the dependent or output variables which are the sources of information, $\theta$ is the weight of independent or input variables and $\varepsilon$ is the random error component. Next, the equation is an equation derived from a function which will be used to run the task of estimation and prediction of a number of available data. This equation can be written as follows:

$$
Y=f\left[v_{0}+\sum_{j=1}^{m} h\left(\lambda_{j}+\sum_{i=1}^{n} x_{i} w_{i j}\right) v_{j}\right]
$$

Where: $\mathrm{Y}=$ Output; $\mathrm{f}=$ The activation function of the layer output; $\mathrm{v}_{0}=$ The output bias; $\mathrm{m}=$ The sum of hidden neuron units; $\mathrm{h}=$ The activation function of the hidden layer; $\lambda_{j}=$ The bias of hidden units $(j=1, \ldots, m) ; n=$ The sum of units serving as input; $\mathrm{x}_{\mathrm{i}}=$ Input vector $(\mathrm{i}=1, \ldots, n) ; \mathrm{w}_{\mathrm{ij}}=$ The weight from input unit $\mathrm{i}$ to the hidden unit $\mathrm{j}$; $v_{j}=$ The weight from the hidden unit $j$ to the output $(j=1, \ldots, m)$. 


\section{METHODOLOGY}

\subsection{Data}

The Indonesian Islamic bank as research population in this research consists of 12 full-fledged Islamic Banks and 22 Islamic windows. This research chooses Bank Syariah Mandiri as a sample since the bank is considered as the largest Islamic bank with asset amounting to Rp82 trillion with a profit reaching Rp180 billion. The data used in this research are primary data collected from Indonesian central bank, and Bank Syariah Mandiri.

Since the Risk Based Bank Rating (RBBR) begins to be implemented in an Indonesian Islamic bank as a basic platform for bank supervision, this research will use the primary parameters in RBBR as input variables which focuses on the three types of risks which are credit risk, liquidity risk, and operational risk.

Initially, the variable selection is conducted through desk study regarding EWS in conventional or Islamic banks. There are 14 variables selected as follow: Credit Risk Parameters consist of Total Financing to Total Asset (TPBY/TA), Financing Income to Total Asset (PPBY/TA), Debt-based Financing to Total Funding, (PUP/TPBY). Non Performing Financing to Total Financing (PBMSLH/ TPBY). Impairment Loss (CKPN) for Murabahah Financing to Total Financing (CKPN/TPBY). Loan Loss Provision to Non-Murabaha Financing (PPAP/TPBY), Asset growth (ASET G); (2) Liquidity Risk Parameters consist of Total Liquid Asset to Total Asset (ALIQ/TA), Total Financing to Total Debt (TPBY/HTG), Total Non-Core Deposit to Total Deposit (NCD/TD); (3) Operational Risks Parameter consist of Wages Expense to Total Asset (BG/TA). Further, this research uses macro economic variables consisting of American dollar exchange rate to rupiah (KURS), Inflation total (INF), interest rate (BI RATE). Meanwhile, the output variables used in this research is the profit value (LABA) obtained from Bank Syariah Mandiri. Further, the collected time series data varying from January 2013 until February 2015 which period are classified into two levels: Validation Level and Testing Level.

\subsection{Method or Estimation Technique}

This research follows Anwar and Mikami (2011) and Anwar and Ismal (2011) who compared the accuracy rate of prediction between statistical method and ANNs. Accordingly, ANNs is found as the best algorithm for making a prediction for the case of Indonesian Islamic bank. Therefore, this research employs ANNs to find the best prediction model according to the accuracy level. The last step is applying the best prediction model to predict the financial performance of Bank Syariah Mandiri. In this step, the researcher will predict the financial performance through in-sample and out of sample data at a bank level. The positive growth of profit and negative growth of profit will be indicated by signs "Up (Naik)" and "Down (Turun)". All steps conducted in this research uses application which name is Alyuda Neuro Intelligence version 2.

\section{RESULTS AND FINDINGS}

Data collected is consisted of 26-time series which are randomly partitioned to be used in the training process $(69.23 \%)$, the validation process $(15.38 \%)$ and testing 
process totaling $15.38 \%$. Afterward, this research conducts variable selection according to the level of significance, architecture selection, prediction model selection and accuracy level testing.

The variable selection process consists of three steps: (1) Designing the ANN's architecture. (2) Providing training to the ANN. (3) Evaluating the reliability of the ANNs. In designing the architecture of ANNs, this research uses the "exhaustive search method" to determine the best ANN architecture. This method consumes a significant amount of time due to fulfilling it is aimed to review all the type of available architecture of the ANNs that may be used. This process is then limited by using the r-squared amounting to 0.000001 as fitness criteria and the amount of iteration totaling 20,000 iterations. The ANNs training process is then conducted by initially setting three configurations. The first configuration employs the logistic function as the activation function on hidden layers. Further, the sum-of-squares errors method is chosen to minimize output errors. Lastly, the expected output is set between 0 and 1 because it uses the logistic function on hidden layers. After the three configurations are set, the ANNs subsequently are trained by using certain limits to avoid over-training conditions which cause non-optimal results. These limits are as follows:

1. The learning algorithm is determined by using the back propagation method.

2. The momentum rate is limited to 0.1 .

3. The training process will be stopped when the mean squared error decreases to 0.000001 or when this process runs until the 20,000 iterations; whichever condition is met first.

4. The last process is conducted to ensure the ANNs is reliable enough in doing its job as selector.

Figure 1. The Importance Level of Each Input Variable

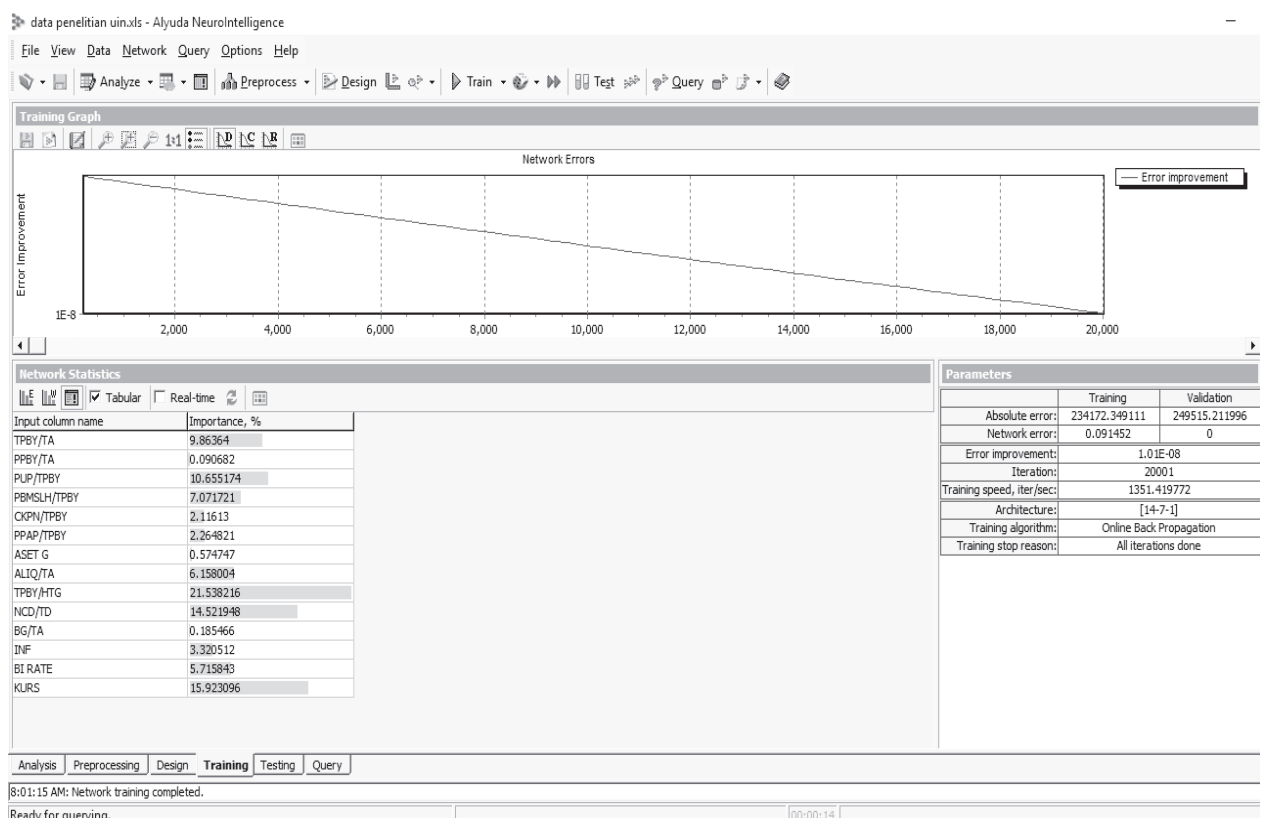


The network reliability will be investigated by using the statistical approach according to correlation value (r), R2, the average absolute error value (AE) and the average relative absolute error value (ARE), as shown in the following picture. Accordingly, the ANNs architecture is selected ANN(14-7-1) which has 3 layers that each input has 14 nodes. Further, the hidden layer consists of 7 nodes and the output layer consists of 1 node (Figure 1).

Based on the selected architecture, ANNs results in 11 input variables which significantly affect the financial risk of Bank Syariah Mandiri which are: Total Financing to Total Debt ratio, Exchange Rate, Total Non Core Deposit to Total Deposit ratio, Debt-based Financing to Total Funding ratio, Total Financing to Total Asset ratio, Non Performing Financing to Total Financing ratio, Total Liquid Asset to Total Asset ratio, Interest Rate, Inflation, Loan Loss Provision to Non-Murabaha Financing ratio, and Impairment Loss for Murabahah Financing to Total Financing ratio. Subsequently, this research is able to proceed to develop a prediction model using the significant variable that selected by ANNs by initially transform the output variables into risk signals (SIGN) which show whether in the next period a bank will experience an increased risk or otherwise. In the prediction model development, this research is required to select the new architecture of ANNs since there is a reduction of 14 input variables into 11 variables. Using similar limitations, Alyuda chooses the ANN(11-2-1) as the best network architecture as depicted in Figure 2.

Figure 2. ANNs' Network Architecture

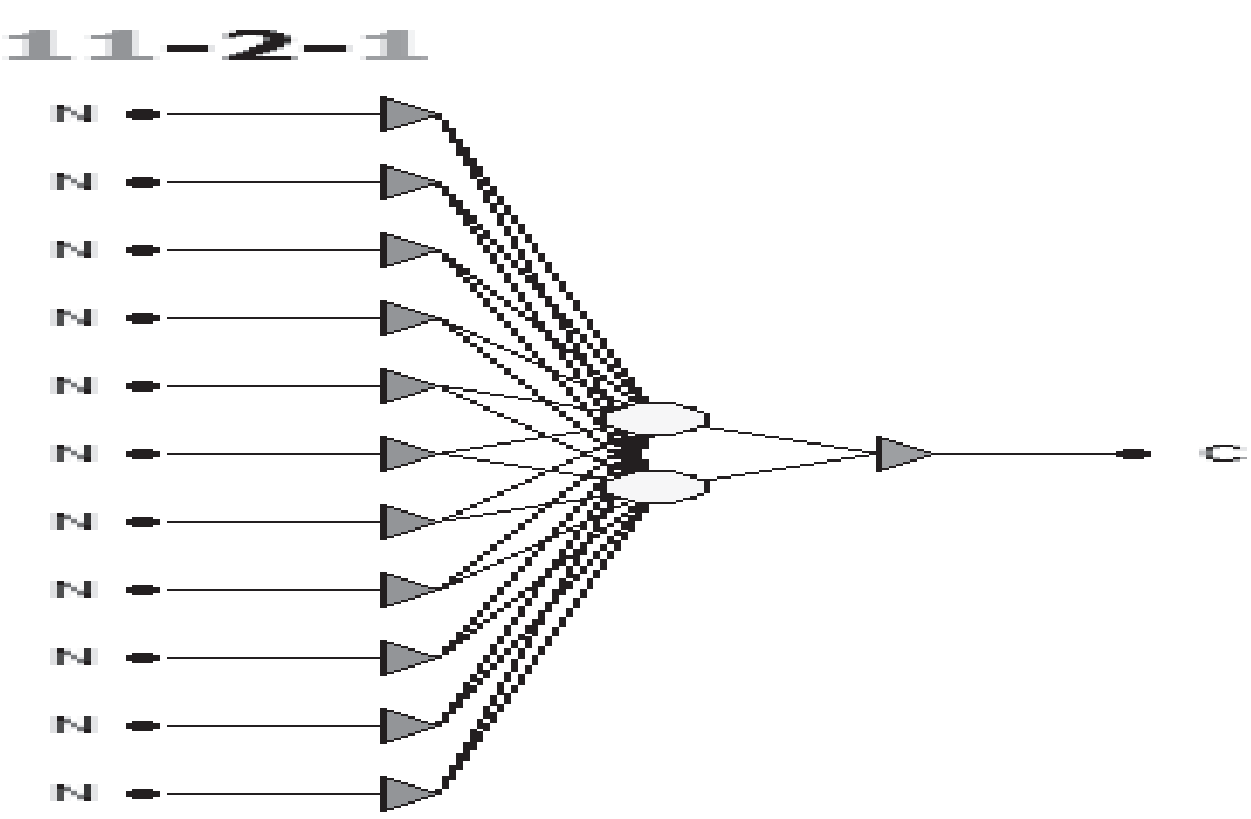




\subsection{Network Training and Validation Step}

In this step, the chosen network is trained to understand the data's conditions so that it can be used to make a prediction. The training process is stopped automatically by Alyuda when the network reaches the lowest error point and does not experience any more improvement. In this learning phase, the network gives weight for each variable as shown in the Figure 3.

Figure 3. The Importance Level of Each Variable

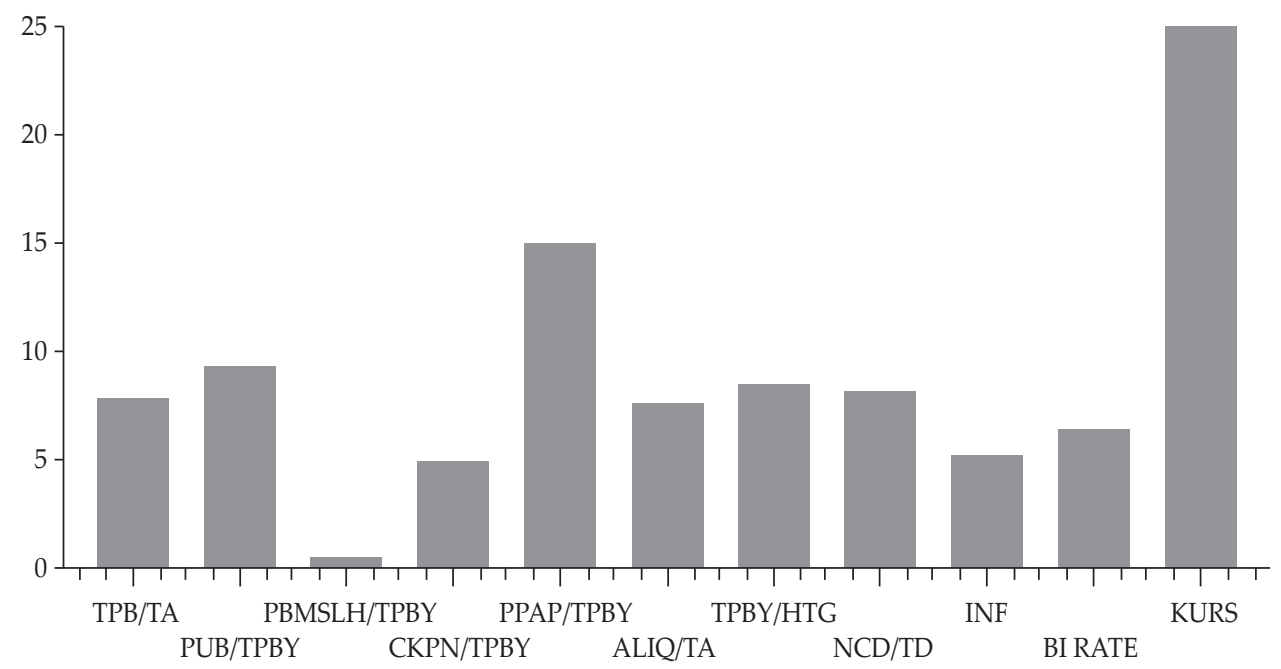

The Figure 3. depicts that almost all variables are considered as having a significant weight in affecting the risk signal of Bank Syariah Mandiri. The exchange rate variable has the largest weight which means that the exchange rate produces a direct impact to the customers who affected by market risks since they buy raw materials from outside the country using USD and sell the product inside the country in Rupiah. Meanwhile, Non-Performing Financing to Total Financing variable has the smallest weight which means the variable is considered to indirectly expose the business risk of the bank.

The network that has been trained is then used to make a prediction. This process uses 17-time series data to run its learning process. The table below depicts the ANN's ability in learning. This learning process produces good enough prediction ability since the network successfully understood the data's behavior results in 58\%, accuracy rate. In the next stage, the network conducts a validation process according to prior knowledge whereas the ANN network successfully understood the data characteristics perfectly (100\%) as shown in the Table 1.

Table 1. The Results of the Prediction in Validation Process

\begin{tabular}{|c|c|c|c|c|c|c|c|c|c|c|c|c|c|c|c|}
\hline & Row & TPBY/TA & PUP/TPBY & PBMSLH/TPBY & CKPN/TPBY & PPAP/TPBY & ALIQ/TA & TPBY/HTG & $\mathrm{NCD} / \mathrm{TD}$ & INF & BI RATE & KURS & Target & Output & Match? \\
\hline VLD & 18 & 0.166411 & 0.769912 & 0.017356 & 0.01926 & 0.020616 & 0.198556 & 0.821079 & 0.684776 & 0.0399 & 0.075 & 12189.06 & Naik & Naik & OK \\
\hline VLD & 19 & 0.165142 & 0.76838 & 0.018326 & 0.018573 & 0.020843 & 0.223461 & 0.809647 & 0.634617 & 0.0456 & 0.075 & 12206.67 & Naik & Naik & OK \\
\hline VLD & 20 & 0.170288 & 0.75875 & 0.01711 & 0.018346 & 0.019429 & 0.225136 & 0.816756 & 0.654784 & 0.0483 & 0.075 & 12390.77 & Naik & Naik & OK \\
\hline
\end{tabular}


Afterwards, the network finally required to be validated. During this phase, the network successfully achieved 75\% accuracy rate which means the ANNs was able to answer 3 data conditions correctly. This accuracy level decreased slightly by $25 \%$ in the validation process since there are only 4 -time series data available (Table 2). However, these results give enough confidence to the researcher that ANN(11-2-1) has produced satisfying results. Accordingly, the ANN(11-2-1) will be used as a prediction algorithm for the early warning system.

Table 2. The Results of the Prediction in Validation Process

\begin{tabular}{cccccccccccccccccc}
\hline & ROW & TPBY/TA & PUP/TPBY & $\begin{array}{c}\text { PBMSLH/ } \\
\text { TPBY }\end{array}$ & $\begin{array}{c}\text { CKPN/ } \\
\text { TPBY }\end{array}$ & $\begin{array}{c}\text { PPAP/ } \\
\text { TPBY }\end{array}$ & ALIO/TA & $\begin{array}{c}\text { TPBY/ } \\
\text { HTG }\end{array}$ & NCD/TD & INF & BIRATE & KURS & Target & Output & Match? \\
\hline TST & 22 & 0.168205 & 0.753462 & 0.014302 & 0.019213 & 0.01657 & 0.233239 & 0.804875 & 0.632029 & 0.0836 & 0.075 & 12658.3 & Naik & Naik & 0 0K \\
TST & 23 & 0.159687 & 0.763987 & 0.012159 & 0.023305 & 0.014517 & 0.250164 & 0.789801 & 0.65826 & 0.0696 & 0.075 & 12938.29 & Naik & Naik & Wrong \\
TST & 24 & 0.157009 & 0.763046 & 0.013027 & 0.024802 & 0.015353 & 0.25937 & 0.77536 & 0.632321 & 0.0629 & 0.0775 & 13079.1 & Naik & Naik & 0 OK \\
TST & 25 & 0.160544 & 0.0758017 & 0.013687 & 0.023513 & 0.016099 & 0.262724 & 0.774115 & 0.625974 & 0.0638 & 0.0775 & 13249.84 & Naik & Naik & OK \\
\hline
\end{tabular}

\subsection{Model Testing}

The last step for the early warning system development is to do testing to the chosen algorithms to predict the risks of Bank Syariah Mandiri by using out-ofsample input variable. Alyuda provides a query tool for inserting out-of-sample data into the network manually. Out-of-sample data means that the data is not yet used in the training, learning, and validation test phase. The data is then recalculated by using the chosen architecture and the weight resulted from the prior step to predict future information as the predicted output variable. The outof sample data used are January and February 2015 are shown in Table 3.

Table 3. The Data Query for Out of Sample Testing

\begin{tabular}{cccccccccccc}
\hline PERIODE & $\begin{array}{c}\text { TPBY/ } \\
\text { TA }\end{array}$ & $\begin{array}{c}\text { PUP/ } \\
\text { TPBY }\end{array}$ & $\begin{array}{c}\text { PBMSLH/ } \\
\text { TPBY }\end{array}$ & $\begin{array}{c}\text { SKPN/ } \\
\text { TPBY }\end{array}$ & $\begin{array}{c}\text { PPAP/ } \\
\text { TPBY }\end{array}$ & ALIQ/TA & $\begin{array}{c}\text { TPBY/ } \\
\text { HTG }\end{array}$ & NCD/TD & INF & BI RATE & KURS \\
\hline Jan-15 & 0.16 & 0.76 & 0.01 & 0.02 & 0.02 & 0.26 & 0.78 & 0.63 & 0.06 & 0.08 & 13079.1 \\
Feb-15 & 0.16 & 0.76 & 0.01 & 0.02 & 0.02 & 0.26 & 0.77 & 0.63 & 0.06 & 0.08 & 13249.84 \\
\hline
\end{tabular}

The predicted output variable will then be compared with the actual condition. Accordingly, during January and February 2015, the EWS will generate a sign that profit will increase which means the risk is decreasing or otherwise. Accordingly, the researcher did an input for February 2015 by manually inputting each variable into the columns provided by Alyuda. Figure 4. depicts the prediction given by the system for January that the profit is predicted to increase where the bank booked profit amounted to Rp52.460 billion. It means the bank will experience a decreasing risk. Accordingly, the system made a prediction with the accuracy of $100 \%$ for January as it is consistent with the actual conditions. 


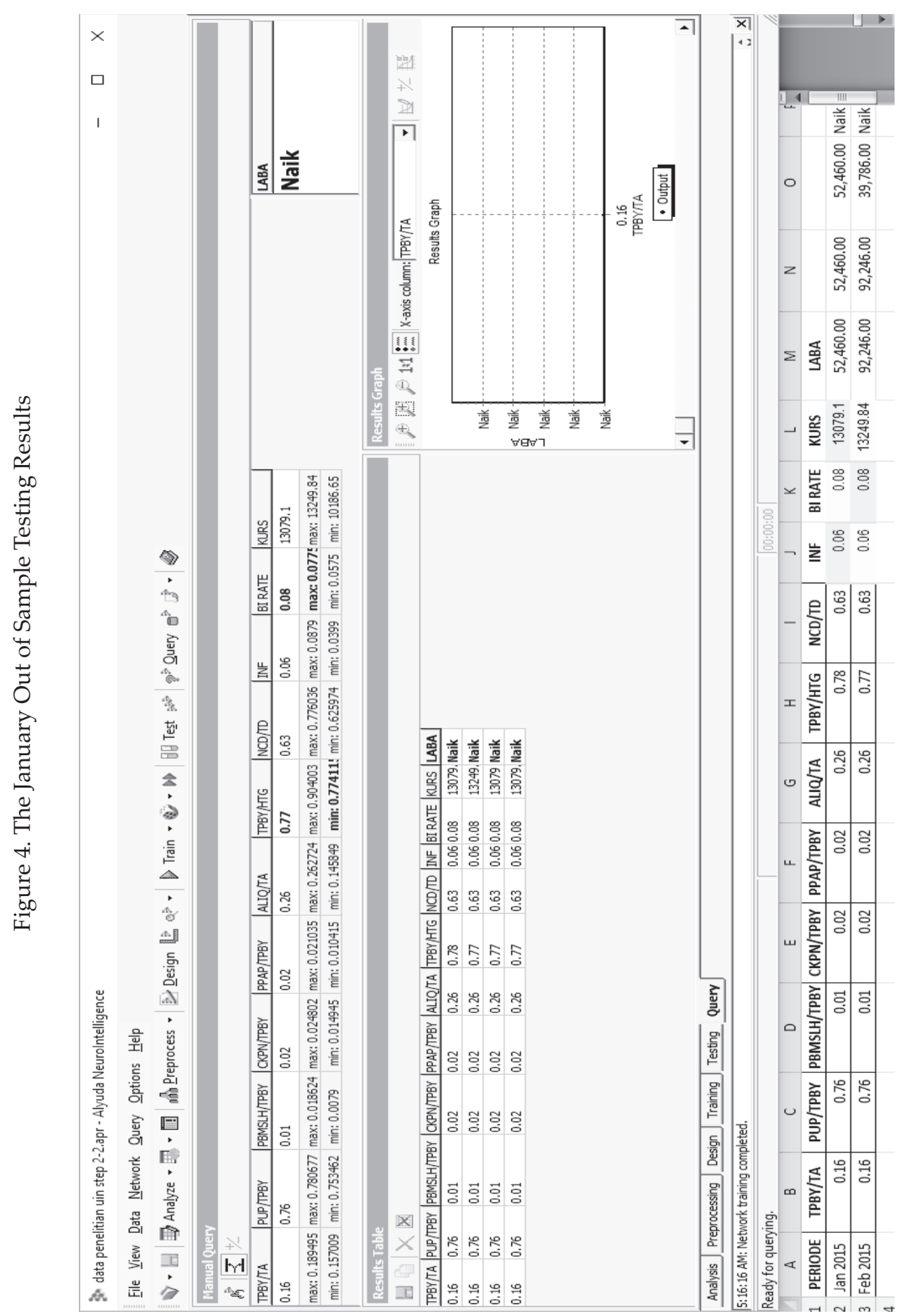




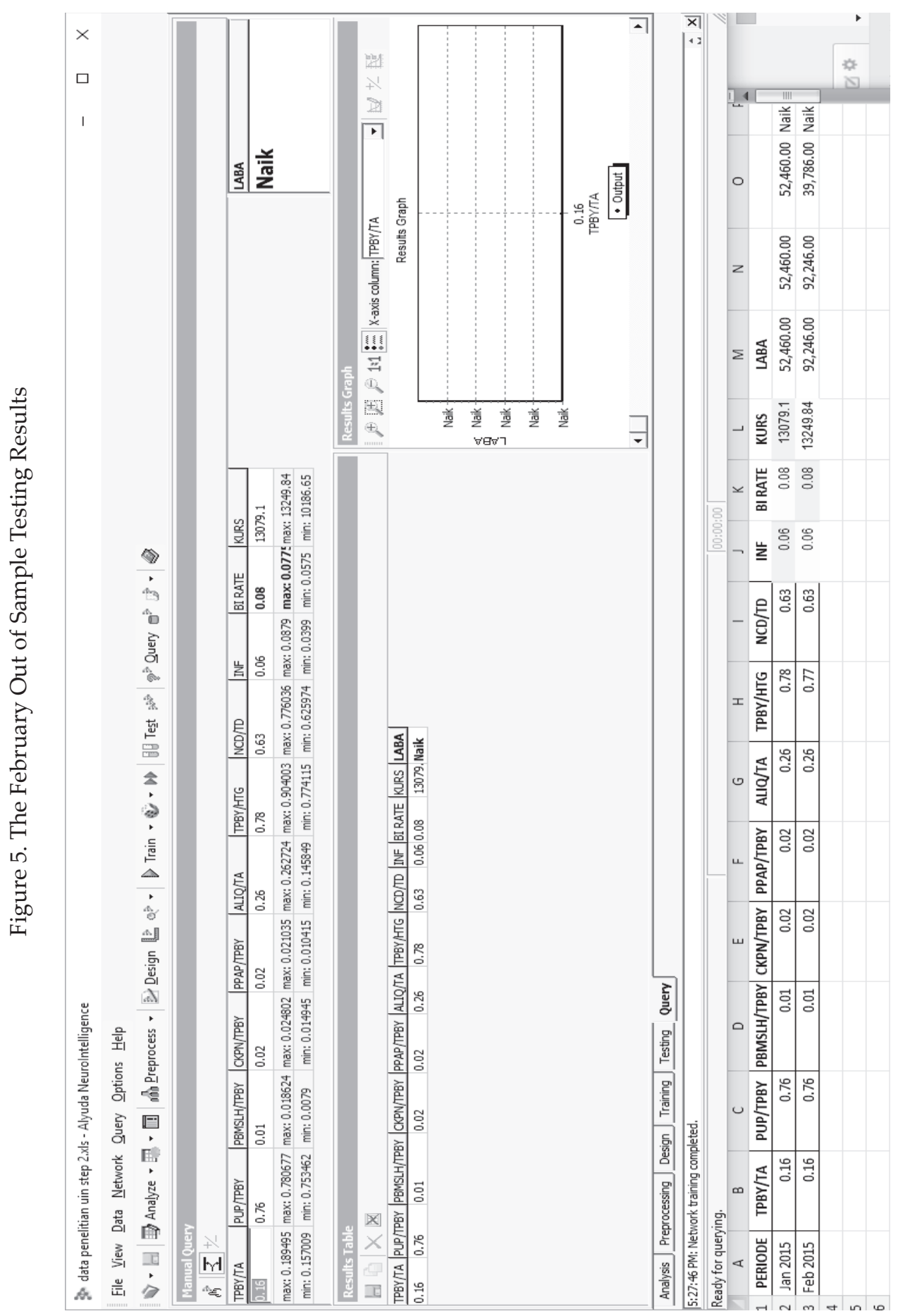


Using the same method, the researchers did an input for February 2015 by manually inputting each variable into the column provided by Alyuda. It can be seen that the system also has the same ability in the February 2015. Figure 5. depicts the prediction given by the system for February 2015 that the profit is predicted to increase while the bank is actually got profit in February was Rp92.246 billion.

According to the prediction result, the proposed EWS system is able to reach $100 \%$ accuracy in predicting two consecutive months using out-of-sample input variables. The result is in line with Bellovary et al. (2007) reported that usage of data mining method such as neural network resulted in accuracy rate in making prediction ranging from $71 \%$ to $100 \%$ since ANNs has a better ability in understanding the context of data pattern variety and its volatility (Anwar and Ismal, 2012). Accordingly, Liao et al, (2012) reported that the usage of data mining method tends to increase. Specifically, Anwar and Ismal (2012) reported that the ANNs empirically provide higher accuracy rate compared to Support Vector Machine method in predicting the profit sharing rate of Islamic banks in Indonesia.

\section{CONCLUSION}

The decreasing financial condition of Islamic banking requires the best effort to resolve. The bankruptcy as the worst impact will not only result in financial and systemic risks but also will endanger the reputation of Islamic law itself. It is too expensive to pay since the Islamic economy is not mature yet and believed to be an alternative system against the capitalistic economy. Therefore, this research attempts to develop a system that can provide early warnings or deliver future information at an early time so that the risk of bankruptcy could be avoided.

The results from this research obtained the conclusion that from 14 variables collected as input variables, there are 11 variables considered to give significant impact in affecting Islamic bank's profitability. Accordingly, the research determines ANN(12-2-1) as the best algorithm that will be embedded in EWS. Finally, the testing results showed that the accuracy level generated by the algorithm using in-sample data is $75 \%$ accuracy rate. Afterwards, it was employed to predict the conditions in the incoming 2 consecutive months by using out-of-sample data which result in $100 \%$ accuracy rate. This indicates that the proposed EWS is suitable to predict bankruptcy risk of Indonesian Islamic bank.

\section{REFERENCES}

Al-Osaimy, M. H. \& Bamakhramah, A. S. (2004). An Early Warning System for Islamic Banks Performance. Islamic Economics, 17(1), 3-14.

Altman, E. I. (1968). Financial Ratios, Discriminant Analysis and the Prediction of Corporate Bankruptcy. Journal of Finance, 589-609.

Altman, E. I. \& Brenner, M. (1981). Information Effects and Stock Market Response to Signs of Firm Deterioration. Journal of Financial \& Quantitative Analysis, 16(1), 35-51.

Altman, E. I. (1993). Corporate Financial Distress and Bankruptcy: A Complete Guide to Predicting \& Avoiding Distress and Profiting from Bankruptcy (2nd Edition ed.). New York: John Wiley \& Sons. Inc. 
Anwar, S., \& Mikami, Y. (2011). Comparing Accuracy Performance of ANN, MLR, and GARCH Model in Predicting Time Deposit Return of Islamic Bank. International Journal of Trade Economics and Finance, 2(1), 44-51.

Anwar, S., \& Ismal, R. (2011, May). Robustness Analysis of Artificial Neural Networks and Support Vector Machine in Making Prediction. Presented at Parallel and Distributed Processing with Applications (ISPA), 2011 IEEE 9th International Symposium on (pp. 256-261). IEEE.

Arena, M., (2008). Bank failures and bank fundamentals: A comparative analysis of Latin America and East Asia during the nineties using bank-level data. Journal of Banking and Finance, 32, 299-310.

Beaver, W. H. (1966). Financial Ratios as Predictors of Failure. Journal of Accounting Research, 4, 71-111.

Bellovary, J. L., Giacomino, D. E., \& Akers, M. D. (2007). A review of bankruptcy prediction studies: 1930 to present. Journal of Financial Education, 1-42.

Chapra, M. U. (2009). The Global Financial Crisis: Can Islamic Finance Help Minimise the Severity and Frequency of Such a Crisis in the Future?. Islam and Civilisational Renewal (ICR), 1(2).

Cybinski, P. (2001). Description, explanation, prediction-the evolution of bankruptcy studies?. Managerial Finance, 27(4), 29-44.

Espahbodi, P. (1991). Identification of Problem Banks and Binary Choice Models. Journal of Banking \& Finance, 15(1), 53-71.

Frydman, H., E. Altman and D. Kao. 1985. Introducing recursive partitioning for Winter 200715 financial classifications: The case of financial distress. The Journal of Finance, 40(1): 269-291.

Gunther, J. W., \& Moore, R. R. (2003). Early warning models in real time. Journal of banking \& finance, 27(10), 1979-2001

Hall, M. J. B., \& Muljawan, D. Suprayogi, \& Moorena, L.(2009). Using the artificial neural network to assess bank credit risk: a case study of Indonesia. Applied Financial Economics, 19(22), 1825-1846.

Keuangan, Otoritas Jasa (2015). Statistik Perbankan Indonesia, from http://www. ojk.go.id/data-statistik-perbankan-indonesia.

Liao, S. H., Chu, P. H., \& Hsiao, P. Y. (2012). Data mining techniques and applications-A decade review from 2000 to 2011. Expert Systems with Applications, 39(12), 11303-11311.

Martin, D. (1977). Early Warning of Bank Failure: A Logit Regression Approach. Journal of Banking \& Finance, 1(3), 249-276.

Meyer, P. A., \& Pifer, H. W. (1970). Prediction of bank failures. The Journal of Finance, 25(4), 853-868.

Othman, J. (2012). Analysing Financial Distress in Malaysian Islamic Banks: Exploring Integrative Predictive Methods. Doctoral dissertation. Durham University.

Pettway, R. H., \& Sinkey, J. F. (1980). Establishing On-Site Bank Examination Priorities: An Early-Warning System Using Accounting and Market Information. The Journal of Finance, 35(1), 137-150.

Takahashi, K., Y. Kurokawa and K: Watase. (1984). Corporate bankruptcy prediction in Japan. Journal of Banking and Finance, 8(2): 229-247. 
Tsang, E., Yung, P., \& Li, J. (2004). EDDIE-Automation, a decision support tool for financial forecasting. Decision Support Systems, 37(4), 559-565.

Wen, W., Chen, Y.H., and Chen, I.C. (2008) "A knowledge-based decision support system for measuring enterprise performance". Knowledge-Based Systems, Vol 21, p.148-163, 2008.

West, P. M., P. L. Brockett, and L. L. Golden (1997), A comparative analysis of neural networks and statistical methods for predicting consumer choice, Marketing Science, 16(4), 370-391. 
This page is intentionally left blank 